\section{CAUGHT IN THE ACT}

I am pleased to submit a photograph of Red Squirrels for Blue Jay. My friend, Margret Falkiner, took the photo near her cottage at Madge Lake. A female Red Squirrel and five of her babies came rushing down a tree trunk making a lot of noise, when suddenly the mother stopped and her young settled down to lunch.

- Isabel Ritchie, Box 1182, Kamsack, Saskatchewan. SOA 1 SO

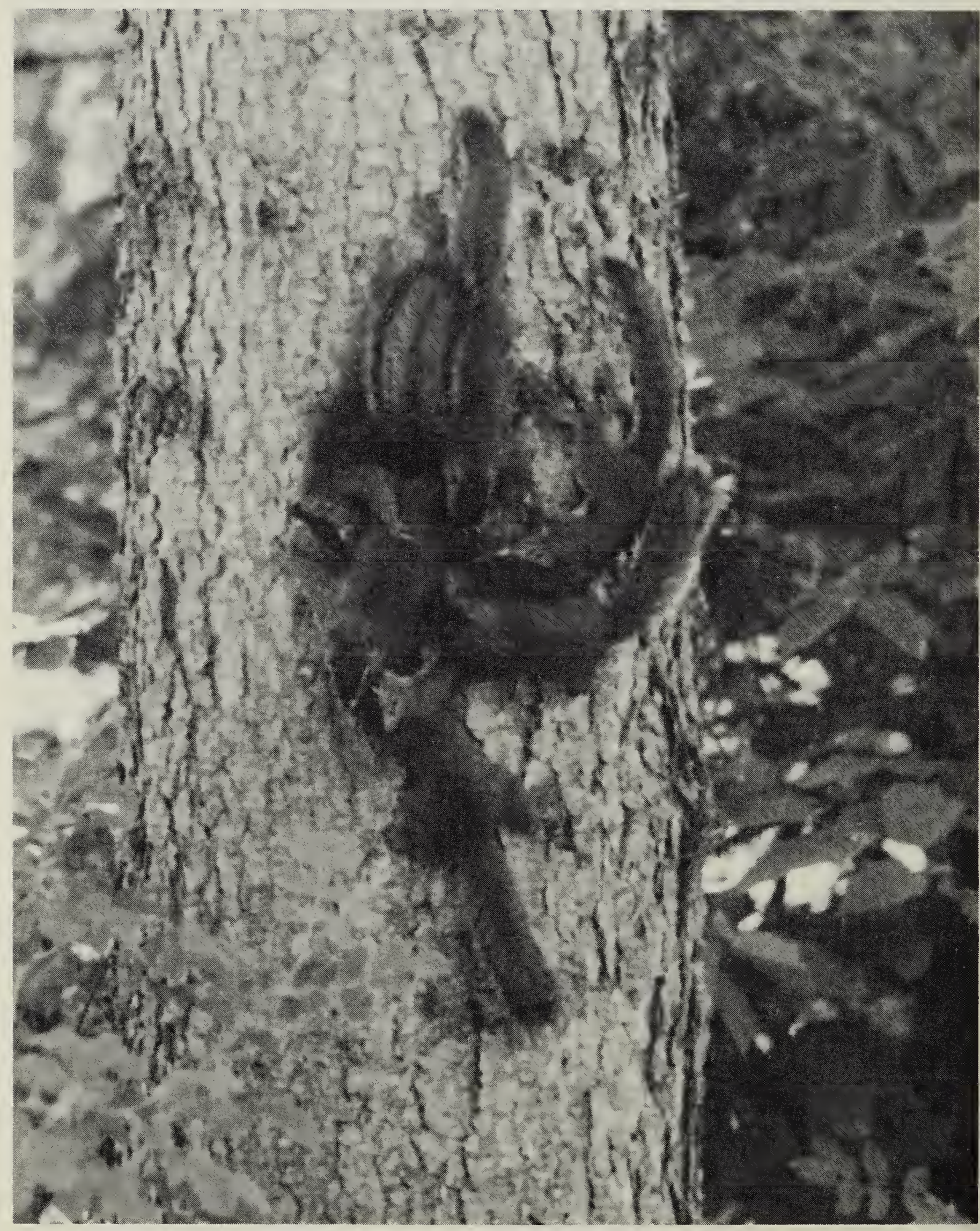

Red Squirrel feeding five of her babies.

Margret Falkiner 


\section{SONG SPARROW AT WINTER FEEDER}

"Larger birds have more feathers than smaller ones, birds living in colder climates have more feathers in winter than in summer, and aquatic species have more feathers than comparably large terrestrial. ones." How about the birds which usually migrate to warmer climates? How do the birds which fail to travel south manage to keep warm enough to survive the severe weather that the prairies can dish out?

We had a reason for wondering, because on 2 December 1993, we noticed a scruffy looking little sparrow at the feeder. It had lost a major portion of the feathers on the left side of its tail. Also, the tip of the left wing was at an awkward upward tilt. It seemed that the bird may have recently escaped from some sort of disaster.

The Song Sparrow would frequent the various feeders; at times it would be in the company of the House Sparrows and the chickadees, but more often it would be alone. It would be the first one at the feeder early in the mornings, it would appear several times during the day, and often, all by itself, it would feed in the fading light of the winter evenings.

When the Song Sparrow first arrived in early December, the central breast spot was barely discernible,

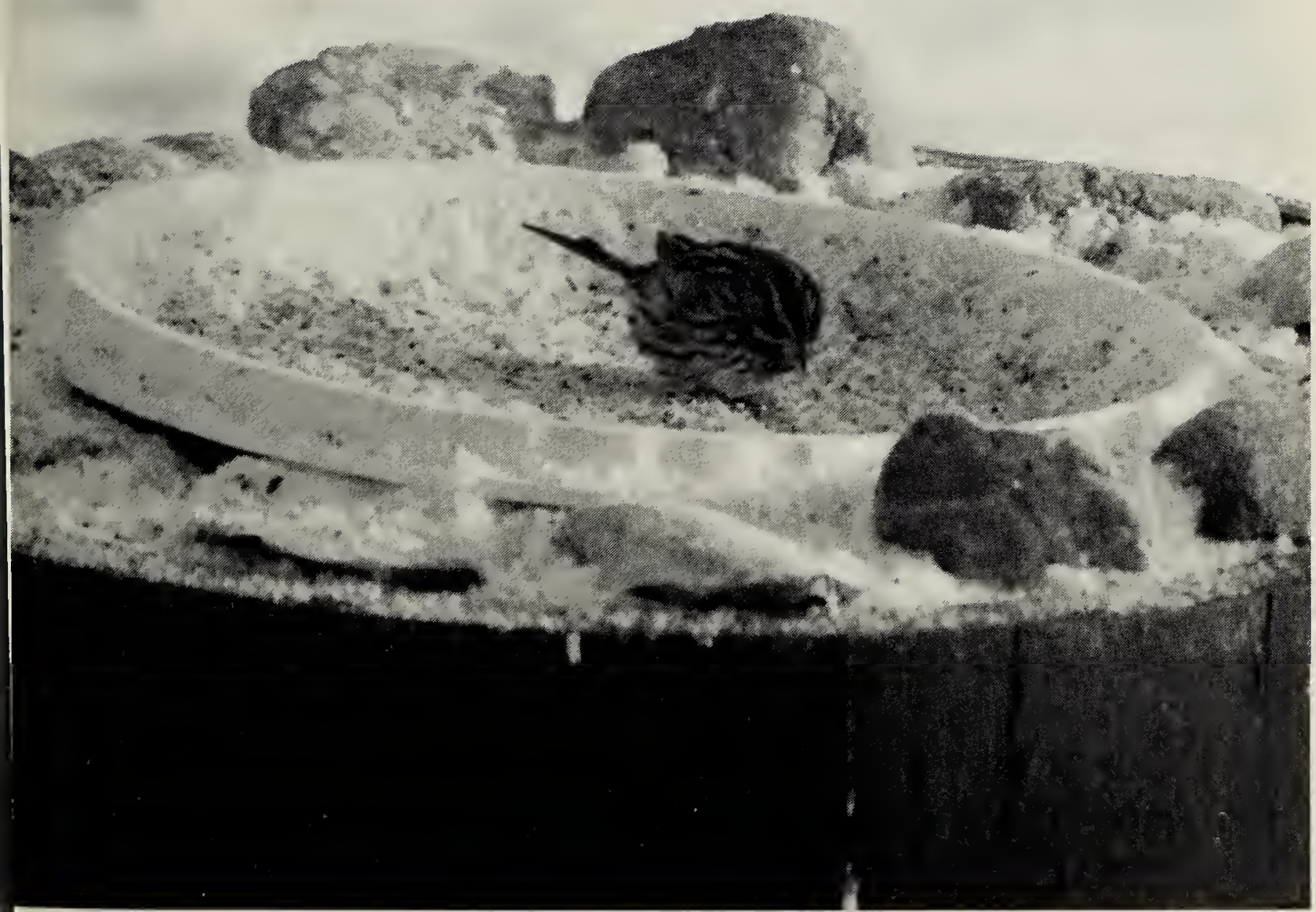


but as time passed the spot became more pronounced, and the injured wing seemed to straighten out. By the end of the month, the bird was looking quite wholesome.

For food, the Song Sparrow would peck away at the smaller seed such as the millet and milo, but seemed to prefer the black oil sunflower seeds. It would do the 'barnyard chicken scratch' with both feet at the same time, much like the juncos do. It would also flick its tail frequently.

Early in February, we realized that the little sparrow was not showing up at the feeders anymore. I had made my last notation about its presence on 4 February 1994. At that time all had seemed well; the bird had looked active and healthy. We wondered what mishap it may have fallen prey to - maybe one of the cats which sometimes wanders into the yard?

1. CORRAL, M. 1989. The world of birds: a layman's guide to ornithology. Globe-Pequot Press, Connecticut. 26 pp.

- Velma Spizawka, Box 47, Spalding, Saskatchewan. SOK 4CO

\section{DOWITCHER FLOCK RESCUES COMPANION FROM MERLIN}

October 7, 1990, was a fine day. I had driven to Monica Slough, a large pond adjacent to Monica Farm near Richardson, Saskatchewan. I stopped on the gravelled road to scan the area with binoculars for any birds of interest. Immediately on my arrival I saw a Merlin pursuing a dowitcher in erratic flight across the sky. They disappeared in a northerly direction but shortly after the Merlin returned, apparently unsuccessful in its pursuit. In the shallow water there was a feeding flock of about 30 dowitchers. The Merlin flew to the nearby farmyard where it probably hunted for sparrows. Suddenly it reappeared at the slough. It was already chasing another dowitcher when I first noticed. They were flying in swift zigzag flight around the slough about five feet above the water when suddenly the whole tight flock of dowitchers took wing and enveloped both pursuer and pursued in a cloud of bodies, wings churning, brushing past the Merlin. For a moment I could see nothing except the flying mass of dowitchers. The Merlin, deprived of its target, broke off the hunt and flew off while the dowitcher flock left the pond.

I described the above incident to Frank Brazier, who felt that the rescue of a companion in peril by a flock of birds was outside anything in any literature that he could remember. The next year, after his return from Australia, he told me that he had recounted the story of the rescue to several professional ornithologists he had met there and none had ever read or heard of anything like it.

- Fred W. Lahrman, \#7 3941 Retallack Street, Regina, Saskatchewan. S4S 3C1 